\title{
O MARCO LEGAL DA BIODIVERSIDADE E SUA APLICAÇÃO NA REGULARIZAÇÃO DAS ATIVIDADES COM O USO DO PATRIMÔNIO GENÉTICO BRASILEIRO
}

\author{
Gesil Sampaio Amarante Segundo \\ Universidade Estadual de Santa Cruz - UESC, professor Titular, docente do Programa de \\ Mestrado em Propriedade Intelectual e Transferência de \\ Tecnologia para a Inovação - PROFNIT \\ Email: gsamarante@uesc.br \\ Luciana Nalim Silva Menuchi \\ Universidade Estadual de Santa Cruz - UESC, advogada, Subgerente de Pós-Graduação, \\ discente do Programa de Mestrado em Propriedade Intelectual e Transferência de Tecnologia \\ para a Inovação - PROFNIT. \\ Email: lnsmenuchi@uesc.br \\ Marcos Rodrigo Trindade Pinheiro Menuchi \\ Universidade Estadual de Santa Cruz - UESC, \\ professor adjunto do Departamento de Ciências da Saúde. \\ Email: mrtpmenuchi@uesc.br \\ Carla Martins Kaneto \\ Universidade Estadual de Santa Cruz - UESC, professora adjunta \\ do Departamento de Biologia. \\ Email: carlakaneto@gmail.com
}

\section{RESUMO}

O patrimônio genético brasileiro, objeto de interesse mundialmente reconhecido, possuía seu uso e proteção regulamentados pela Medida Provisória (MP) $\mathrm{n}^{\mathrm{0}}$ 2.186-16/2001. Após mais de 15 anos de vigência, a MP foi revogada pela Lei ${ }^{\circ} 13.123 / 2015$, que, em conjunto com o Decreto $\mathrm{n}^{\mathrm{o}} 8.772 / 2016$, apresentou novos procedimentos para o uso e exploração econômica do patrimônio genético nacional e do conhecimento tradicional associado. O Marco Legal da Biodiversidade (MLB), como ficou conhecido o conjunto legislativo em vigor, trouxe em suas disposições transitórias procedimentos de ajuste obrigatório de atividade para aqueles que utilizaram a biota nacional na vigência da MP sem a observação dos procedimentos impostos à época. As disposições transitórias devem ser adimplidas pelos usuários nacionais e internacionais, dentro do prazo de 1 ano, a contar de 06 de novembro de 2017, sob pena de aplicação de penalidades ao pesquisador e instituição a que está vinculado e, ainda, ao 
importador de produtos fabricados no exterior com o uso de patrimônio genético e conhecimento tradicional brasileiros. Diante desta nova demanda legislativa, o presente estudo teve como objetivo interpretar as normas legais e apresentar de forma sistemática os procedimentos a serem adotados pelos usuários, para o cumprimento das normas transitórias do MLB.

Palavras-chave: Patrimônio genético; Lei n 13.123/2015; Biodiversidade; Marco Legal da Biodiversidade.

\title{
THE BIODIVERSITY LEGAL FRAMEWORK AND THE ENFORCEMENT TO REGULARIZE ACTIVITIES WITH BRAZILIAN GENETIC HERITAGE
}

\begin{abstract}
The Brazilian genetic heritage, object of world-renowned interest, had its use and protection regulated by the Provisional Measure (PM) $n^{\circ} 2.186$ $16 / 2001$. After nearly 15 years of validity, this PM was substituted by the Law number 13,123 of 2015, which, together with the Decree 8,772 /2016, introduced new procedures for the use and the economic exploitation of the national genetic heritage and the traditional knowledge associated to the genetic heritage. The Legal Framework for Biodiversity (LFB), as this legal set of instruments became known, brought into its transitional provisions mandatory activity adjustment procedures for those who have accessed the national biota by the time of the validity of the MP 2.186-16/2001 and have failed observing its procedures. The transitional provisions must be complied with by national and international users, within a period of one year from November 6, 2017, so as to avoid penalties to the researcher, the institution and even to the importer of manufactured products made abroad with the use of genetic heritage and traditional Brazilian knowledge. In view of this new regulation, the present study has interpreted the norms and systematically presented the procedures to be adopted by the users, in order to comply with the transitional norms of the LFB.
\end{abstract}

Keywords: Genetic heritage; Law $n^{\circ}$ 13.123/2015; Biodiversity; Legal Framework for Biodiversity. 


\section{INTRODUÇÃO}

A proteção e a regulamentação do uso do patrimônio genético brasileiro tem sido tema de debate da comunidade científica nacional e internacional (FERREIRA E SAMPAIO, 2013; FERRO et al., 2006; SACCARO, 2011). O Brasil, como maior detentor do patrimônio genético mundial, abriga aproximadamente $13 \%$ de toda a biodiversidade disponível no mundo (LEWINSOHN, T. M. \& PRADO, P. I., 2006; VASCONCELOS, 2012), com riqueza de espécies e elevado grau de endemismo, tanto no nível de espécies quanto de categorias taxonômicas superiores (FERREIRA E SAMPAIO, 2013; MITTERMEIER, 1997; GERRA et al., 2015).

A Constituição Brasileira de 1988 reconheceu o valor intrínseco dos recursos naturais existentes no país ao inserir, de forma expressa, em seu artigo 225, a garantia a um meio ambiente ecologicamente equilibrado e o dever coletivo de preservar e defender o patrimônio ambiental nacional (BRASIL, 1988). Não obstante a previsão constitucional, a regulamentação de uso e proteção da biota nacional somente veio a ocorrer anos depois, após a ratificação da Convenção sobre a Diversidade Biológica (CDB), que elevou os recursos genéticos e o conhecimento tradicional das comunidades quando associados a estes, a bens de uso e disposição soberana dos Estados, respeitados a Carta das Nações Unidas e os princípios de Direito Internacional (BRASIL, 1994).

Após a incorporação no ordenamento jurídico nacional da CDB, por meio do decreto $\mathrm{n}^{\circ} 2.519$ (BRASIL, 1998), diversos projetos de lei e uma proposta de emenda à Constituição tramitaram no Congresso Nacional com o objetivo de regulamentar o acesso e a proteção do patrimônio genético brasileiro. Contudo, em que pese a propositura desses projetos, alguns autores consideram que estes não foram devidamente discutidos e tramitados, gerando lacunas jurídicas que dificultaram a proteção da biodiversidade nacional e a repartição dos benefícios auferidos com o uso da biota (BRASIL, 1998; AZEVEDO, 2005; GODINHO e MACHADO, 2011).

Destaca-se o caso do acordo entre a Novartis Pharma AG (empresa multinacional de fármacos sediada na Suíça) e a Organização Social Bioamazônia, responsável pelo Programa Brasileiro de Ecologia Molecular para o Uso Sustentável da Amazônia. Neste acordo estava previsto que a Novartis teria o direito de acesso e uso exclusivo do material genético existente no território amazônico, em troca de benefícios irrisórios 
(BENSUSAN, 2003; GODINHO E MACHADO, 2011; MENUCHI et al., 2016). A comoção nacional e as lacunas jurídicas, existentes pela ausência de regulamentação da $\mathrm{CDB}$, permitiram a anulação do acordo (BENSUSAN, 2003).

Neste contexto, a ausência, tanto de regulamentação nacional para o uso do patrimônio genético nacional como de pressão popular contrária ao acordo entre a Bioamazônia e a Novastis, ensejou a edição da Medida Provisória (MP) n 2.186, que entrou em vigor no dia 29 de junho de 2000, regulamentando o acesso a componente do patrimônio genético (PG) e ao conhecimento tradicional associado (CTA) (BRASIL, 2001).

No entanto, a MP, editada nesse cenário, ignorou os projetos de leis e a emenda constitucional em tramitação, bem como os debates no meio acadêmico e social (MENUCHI et al, 2016), acabando por criar dificuldades burocráticas e imprecisões conceituais que inviabilizaram a realização de pesquisa científica, bioprospecção e desenvolvimento tecnológico no país (NADER et al., 2017; AZEVEDO, 2005; SACCARO, 2011; TÁVORA et al., 2015).

Ante a inaptidão da MP (reeditada 16 vezes até 2001) em cumprir seus objetivos, e diante das inúmeras críticas apresentadas, principalmente pela comunidade científica, o Executivo foi levado a apresentar o projeto de lei $n^{\circ} 7.735 / 2014$, resultando em 20 de maio de 2015 na Lei $n^{\circ} 13.123$, a qual revogou a Medida Provisória $n^{\circ}$ 2.186-16/2001 e, posteriormente, foi regulamentada pelo Decreto ${ }^{\circ}$ 8.772/2016 (BRASIL, 2015; BRASIL, 2016; MOREIRA et al., 2017). Este novo conjunto legislativo é considerado hoje como o Marco Legal da Biodiversidade (MLB), pois apresenta novos procedimentos a serem observados no uso da biota brasileira (BRASIL, 2015; FERREIRA E SAMPABIO, 2013; FERRO et al., 2006; NADER et al., 2017).

O MLB não está restrito a novos procedimentos iniciados após sua entrada em vigor. Em seu texto há a previsão do prazo de um ano para a reformulação, regularização e adequação de diversas atividades desenvolvidas de forma irregular durante a vigência da MP. Esse prazo teve sua contagem iniciada no dia 06 de novembro de 2017, quando foi disponibilizado o Sistema Nacional de Gestão do Patrimônio Genético e do Conhecimento Tradicional Associado (SisGen) (BRASIL, 2017d). Como sanção ao descumprimento deste prazo, destaca-se a aplicação de multa pecuniária a instituição ou empresa e também à pessoa física a elas vinculada, no montante variável de $\mathrm{R} \$ 1.000,00$ (mil reais) a 10.000.000,00 
(dez milhões de reais) (BRASIL, 2015; BRASIL, 2016).

Em razão das novas disposições e do reduzido prazo para regularização das atividades, torna-se fundamental a compreensão dos procedimentos e das atividades que envolvem o patrimônio genético brasileiro. Assim, o objetivo deste estudo é apresentar,de forma sistemática, as atividades a serem ajustadas (reformuladas, adequadas ou regularizadas) e os procedimentos a serem adotados pelos usuários, para o cumprimento das normas transitórias do MLB. Este artigo está organizado em função dos conceitos e delimitações das atividades e procedimentos descritos no MLB.

\section{DO ALCANCE E DAS NORMAS DE TRANSIÇÃO}

As normas de transição, previstas no capítulo VIII da Lei $\mathrm{n}^{0}$ 13.123/2015 e também no Decreto $n^{\circ} 8.772 / 2016$, devem ser aplicadas às atividades realizadas na vigência da medida provisória $(30.06 .2000$ a 16.11.2015), as quais, na época de sua realização, não cumpriram ou apenas cumpriram parcialmente as exigências previstas na MP (BRASIL, 2015; 2016).

A figura 1 apresenta os marcos temporais que definem as atividades sujeitas à aplicação das normas transitórias.
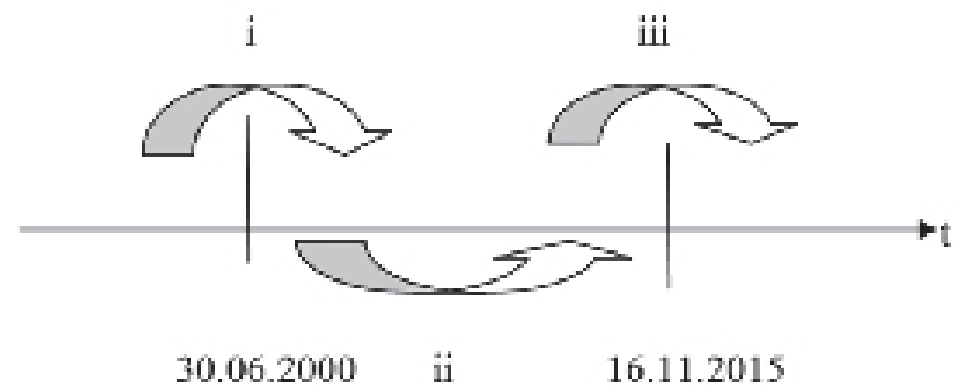

Figura 1. Marcos temporais que definem as atividades sujeitas à aplicação das disposições transitórias do capítulo VIII da Lei $n^{0}$ 13.123/2015 e do Decreto ${ }^{\circ} 8.772 / 2016$.

De acordo com a figura 1, as normas de transição abrangem: i) atividades iniciadas antes da vigência da MP, em 30.06.2000, mas, ainda em andamento de forma irregular, a partir desta data; ii) atividades iniciadas e finalizadas de forma irregular durante a vigência da MP (30.06.2000 a 
16.11.2015); e iii) atividades iniciadas regularmente durante a MP e em andamento após o início da vigência da Lei, em 17.11.2015 (BRASIL, 2015; 2016).

O MLB traz uma distinção quanto ao procedimento de ajuste para as atividades a serem reformuladas, regularizadas e aquelas a serem adequadas. Consideram-se, para fins de ajuste, as atividades que estavam previstas na Medida Provisória. As ações que não constavam no rol de previsões da MP e foram fruto de inovação do novo conjunto legislativo não estão enquadradas na norma de transição e, portanto, não necessitam de reparo. Assim, deverão ser adequadas as atividades enquadradas no item ii, regularizadas as enquadradas nos itens $\mathbf{i}$ e iii da figura $1 \mathrm{e}$, reformuladas, as atividades enquadradas no item iii que aguardavam a tramitação do pedido de cadastro ou autorização para realização de atividade (BRASIL, 2015; 2016).

Em sentido amplo, o Decreto ${ }^{\circ} 8.772 / 16$ elenca no artigo $3^{\circ}, \S 2^{\circ}$, os meios através dos quais uma atividade seria considerada finalizada, permitindo-se ao Conselho de Gestão do Patrimônio Genético (CGEN) definir outros meios de encerramento. Essa delimitação se torna importante para o enquadramento temporal das atividades e para a identificação do procedimento a ser adotado (BRASIL, 2016).

Dois princípios jurídicos norteiam a interpretação das disposições transitórias do MLB. O primeiro é o da segurança jurídica, que garante a estabilidade social e protege os cidadãos de alterações repentinas no ordenamento jurídico posto. Segundo esse princípio, alterações supervenientes das normas jurídicas não podem retroagir para alcançar situações já consolidadas, garantindo-se assim a confiança nas normas vigentes (MEIRELLES, 2016). O segundo é o princípio constitucional da não retroatividade da lei, que estabelece no artigo $5^{\circ}$, inciso XXXVI da Constituição Federal, que a lei não poderá retroagir para prejudicar o direito adquirido e o ato jurídico perfeito (BRASIL, 1988; MEIRELLES, 2016). O respeito ao ato jurídico perfeito significa proibir que uma nova lei demande novas exigências, definições e consequências diversas daquelas existentes na época da realização do ato que preencheu todos os elementos necessários a sua formação (BRASIL, 1988).

O princípio da não retroatividade da lei impossibilita a aplicação de lei posterior mais benéfica, quando já aplicada sanção administrativa na vigência de lei revogada (JUSTEM FILHO, 2005). Desta forma, aqueles que receberam sanções na época da vigência da MP não serão anistiados 
em razão do MLB deixar de enquadrar determinada conduta como infração administrativa.

Com base em ambos os princípios, as atividades iniciadas e finalizadas durante a vigência da MP e que estavam de acordo com esta, não deverão ser ajustadas, as sanções administrativas aplicadas não poderão ser alteradas e, ainda, os conceitos utilizados para definir uma atividade deverão ser os que vigoravam na época de sua realização (BRASIL, 1942).

\section{ATIVIDADES QUE DEVERÃO SER AJUSTADAS}

O Capítulo VIII da Lei e o Decreto descrevem as normas de transição e relacionam as atividades que deverão ser reformuladas, adequadas ou regularizadas, prevendo procedimento diverso para cada forma de ajuste. Especificamente, os artigos 35, 37 e 38 da Lei ${ }^{\circ}$ 13.123/2015 relacionam quais atividades devem ser ajustadas obrigatoriamente. São elas: i) o acesso ao patrimônio genético; ii) o acesso ao conhecimento tradicional associado; iii) o acesso e exploração econômica de produto ou processo oriundo do acesso ao PG ou CTA; iv) a remessa ao exterior do PG; v) a divulgação, transmissão ou retransmissão de dados ou informações que integram ou constituem CTA, e vi) os pedidos de autorização e regularização que estavam em tramitação na entrada em vigor do MLB (BRASIL, 2015).

As atividades e suas definições reconhecidas e aceitas na época da vigência da MP são apresentadas abaixo, interpretando-se e relacionandose os procedimentos de adequação e regularização para cada ação individualmente.

\subsection{Acesso ao Patrimônio Genético}

A primeira atividade prevista no MLB como de ajuste obrigatório é a de acesso ao patrimônio genético. $\mathrm{O}$ artigo $7^{\circ}$, I da MP definia patrimônio genético como:

\footnotetext{
“informação de origem genética, contida em amostras do todo ou de parte de espécime vegetal, fúngico, microbiano ou animal, na forma de moléculas e substâncias provenientes do metabolismo destes seres vivos e de extratos obtidos destes organismos vivos ou mortos, encontrados em condições in situ, inclusive domesticados, ou mantidos em coleções ex situ, desde que coletados em condições
} 
in situ no território nacional, na plataforma continental ou na zona econômica exclusiva"(BRASIL, 2001).

O bem a ser protegido pela MP e pelo MLB é o bem nativo, proveniente da biodiversidade brasileira, ou exótico, desde que tenha adquirido características próprias no território nacional, seja ele animal, fúngico, microbiano ou vegetal (BRASIL, 2001; VASCONCELOS, 2012).

A delimitação do alcance dessa expressão foi objeto de muitas dúvidas durante a vigência da MP.

$\mathrm{Na}$ definição de 'patrimônio genético, a palavra 'informação' merece ser destacada. Esta tem por finalidade relacionar a atividade de acesso a uma atividade imaterial, ou seja, a informação biológica a ser utilizada pode ser acessada por outros meios que não apenas diretamente do material genético em si. Como exemplo, pode-se considerar a reprodução do desenho de uma molécula em um artigo científico. Este desenho possibilitaria, em tese, a reconstrução da molécula, dispensandose a obtenção do material genético de forma direta. Neste sentido, o uso de informação de origem genética extraída de artigo científico deveria ter obedecido às regras dispostas na MP, ou seja, deveria ter obtido junto aos órgãos competentes a autorização para a realização de acesso, uma vez que o local da coleta da amostra/informação é irrelevante (BRASIL, 2001; LAVRATTI, 2007; VASCONCELOS, 2012). Importante destacar que a "informação" incorpora não apenas o DNA e o RNA, mas também todo material que contiver informações de origem genética, como por exemplo, as biomoléculas, alvo frequente de bioprospecção (LAVRATTI, 2007).

Outras expressões contidas no conceito que podem ensejar dúvidas são aquelas referentes ao "[...] território nacional, plataforma continental e na zona econômica exclusiva" (art. $7^{\circ}$, I da MP). No entanto, para estas, o interessado poderá consultar a Lei $n^{\circ} 8.617 / 1993$, a qual traz uma definição precisa sobre as expressões mencionadas (BRASIL, 1993).

No mais, para a compreensão do termo "acesso", faz-se necessária a interpretação conjunta do inciso IV do artigo $7^{\circ}$ da MP e da Orientação Técnica (OT) n ${ }^{\circ}$ 01/2003 do CGEN (BRASIL, 2003). A palavra acesso deve ser entendida como: a obtenção de amostra do patrimônio genético com o objetivo de isolar, identificar ou utilizar as informações de origem genética ou as substâncias e moléculas oriundas do metabolismo de seres vivos ou de extratos destes organismos (VASCONCELOS, 2012; BRASIL, 
2003; BRASIL, 2001). Assim, a simples coleta do material, ou seja, a retirada de uma amostra biológica do seu habitat natural, não é considerada acesso, pois lhe falta o uso com a finalidade de isolar, identificar ou utilizar a informação contida nesta amostra coletada. Isto é, a simples coleta não gera a obrigação de ajuste imposta pela norma de transição.

Para fins de ajuste, a data da atividade que deverá ser considerada é aquela em que o acesso foi realizado e não a data em que a coleta ocorreu. Por exemplo, se a amostra foi coletada antes do início da vigência da MP (30.06.2000), mas o seu acesso -ou seja, o isolamento, a identificação ou a utilização das informações genéticas contidas nesta amostra - somente veio a ocorrer após a entrada em vigor da MP, esta atividade deverá ser ajustada nos termos do MLB.

\subsubsection{Atividades não enquadradas como acesso ao patrimônio genético}

Durante a vigência da $\mathrm{MP}$, diversas atividades não foram consideradas como acesso ao patrimônio genético e, portanto, não devem cumprir as normas de transição impostas no MLB. Algumas porque a MP, as Orientações Técnicas (OT) e as Resoluções expedidas pelo CGEN expressamente as excluíam, outras porque acordos internacionais ratificados pelo Brasil impediam o alcance da MP (LENZA, 2015).

Destacam-se abaixo as atividades que não eram consideradas acesso ao patrimônio genético:

a) Atividades de acesso e remessa de amostras dos recursos fitogenéticos, mantidos em condições ex situ, quando realizadas exclusivamente para pesquisa, conservação, treinamento e melhoramento, desde que vinculados à alimentação e à agricultura regidas pelo Tratado Internacional sobre Recursos Fitogenéticos para a Alimentação e Agricultura - TIRFAA (BRASIL, 2008; BRASIL, 2013).

O Anexo I do Decreto $\mathrm{n}^{\circ} 6.476 / 2008$, que incorporou o TIRFAA ao ordenamento jurídico brasileiro, traz a relação das espécies que estão incluídas no Tratado (BRASIL, 2008). Observa-se que as atividades previstas no TIRFAA, quando realizadas a partir de materiais mantidos em condições in situ ou, quando tiverem por objetivo o uso químico, farmacêutico ou outros usos industriais não vinculados a alimentos animais ou humanos, deveriam ter cumprido as regras da MP e, portanto, estão abrangidas pelas normas de transição do MLB (FERREIRA E 
CLEMENTINO, 2010; BRASIL, 2013).

Os tratados internacionais que não sejam de direitos humanos, quando incorporados no ordenamento jurídico pátrio, passam a ter caráter de norma infraconstitucional equivalente ao da lei ordinária, que é hierarquicamente superior às Medidas Provisórias. Portanto, as normas contidas em um tratado equiparado a lei ordinária não podem ser restringidas por uma Medida Provisória (LENZA, 2015).

b) Pesquisas e testes para aferição de taxa de mortalidade, crescimento ou multiplicação de parasitas, pragas ou vetores de doenças, quando visaram exclusivamente à investigação das propriedades das moléculas ou compostos químicos, naturais ou sintéticos (BRASIL, 2014a).

c) Uso de informações contidas em banco de dados nacionais e internacionais de domínio público, como, por exemplo, o GenBank, Genome, UniGene e outros (https://www.ncbi.nlm.nih.gov/) (BRASIL, 2014b).

d) Os óleos essenciais ou fixos e os extratos comerciais estão dispensados de ajuste, quando o isolamento, a extração ou a purificação resultarem em um produto final com característica basicamente equivalente à matéria prima que lhe deu origem (RESOLUÇÃO No 29/07; FERREIRA E CLEMENTINO, 2010; GODINHO e MACHADO, 2011).

e) Nos programas de melhoramento genético, a etapa de pré-melhoramento e de seleção propriamente (ex. testes de progênie e seleção massal), enquadram-se como pesquisa científica e estavam excluídos das hipóteses de incidência da MP (FERREIRA E CLEMENTINO, 2010).

f) Pesquisas que tiveram por objetivo a avaliação e a elucidação da evolução histórica de uma espécie ou grupo taxonômico, as relações entre os próprios seres vivos ou entre estes e o meio ambiente ou, a variedade genética de populações, conforme previsto na Resolução $n^{\circ}$ 28/07 do CGEN (BRASIL, 2007c).

Observa-se que a exclusão prevista na Resolução restringe-se à atividade de pesquisa (BRASIL, 2007c). Desta forma, as demais atividades que derivarem desta, como, por exemplo, a geração de produtos e processos, não estariam abrangidas pela exclusão e, portanto, deverão ser ajustadas conforme as disposições transitórias do MLB. 
g) Atividade científica para testes de filiação, técnicas de sexageme análises de cariótipo ou de $A D N$ que objetivem a identificação de uma espécime ou espécie (BRASIL, 2007c).

h) Pesquisas epidemiológicas ou as que buscavam a identificação de agentes etiológicos de doenças, bem como a mensuração da concentração de substância conhecida que indicasse doença ou estado fisiológico a depender da concentração no organismo (BRASIL, 2006).

i) Pesquisas que tinham por finalidade a composição de coleções de germoplasma, DNA, sangue, tecidos e soro (BRASIL, 2006).

j) Patrimônio genético humano, excluído de forma expressa pelo artigo $3^{\mathrm{a}}$ da MP (BRASIL, 2001).

k) Espécies vegetais e animais que foram introduzidas no Brasil, encontradas em condições in situ que formam populações espontâneas, mas que, porém, não tenham adquirido características distintivas próprias no Brasil (BRASIL, 2016).

O Ministério da Agricultura, Pecuária e Abastecimento publicará periodicamente lista indicando as espécies que formam populações espontâneas e variedades que tenham adquirido propriedades características no Brasil (BRASIL, 2016). A primeira lista pode ser encontrada na instrução normativa $\mathrm{n}^{\circ} 23$ (BRASIL, 2017a).

Em que pese esta exclusão ter sido proveniente do MLB e não da MP, a sua aplicação é imediata, pois se trata de norma regulamentadora de sentido técnico que delimita o alcance da nacionalidade do patrimônio genético e, com isso, a abrangência das normas brasileiras (GAGLIANO e STOLZE, 2012).

1) A utilização de patrimônio genético como excipiente nos produtos de higiene pessoal, perfumaria e cosméticos (BRASIL, 2017c).

A Orientação Técnica ${ }^{\circ}$ 02/2017 definiu que, na hipótese acima descrita, considera-se como excipiente o PATGE utilizado exclusivamente na estrutura da fórmula, responsável pelo aspecto físico, consistência e estabilidade, e que não determine funcionalidade ao produto (BRASIL, 2017c). 
m) Atividades desenvolvidas referentes a variedades cultivadas de canade-açúcar (Saccharum spp), por estas variedades não serem consideradas patrimônio genético brasileiro (BRASIL, 2007b).

Finalmente, todas as atividades de acesso ao patrimônio genético não elencadas nas hipóteses de exclusão acima descritas, e que não tenham sido realizadas de acordo com as determinações da MP ou que estavam em andamento quando da entrada em vigor do MLB, deverão ser ajustadas conforme determinado pela legislação em vigor.

\subsubsection{Procedimento de ajuste}

Para a regularização da atividade de acesso ao patrimônio genético, devem ser observados a data de sua realização e o local onde ocorreu o acesso (BRASIL, 2016).

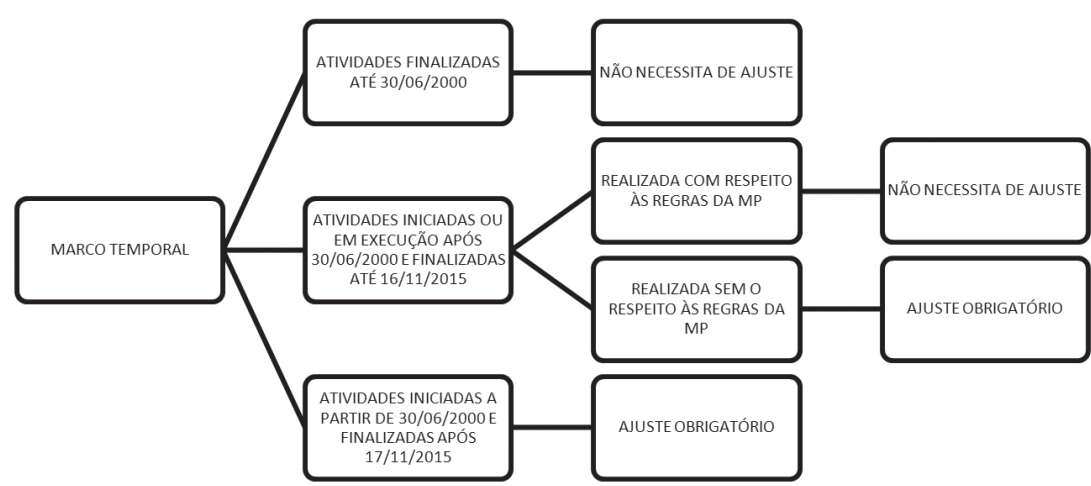

Figura 2. Descrição esquemática das hipóteses dos Marcos Temporais sobre a obrigatoriedade de regularização das atividades com o uso da biodiversidade brasileira

Se o acesso ao patrimônio genético ocorreu entre 30.06.2000 e 16.11.2015 em desacordo com as regras da MP, o usuário necessitará efetuar o cadastro da atividade no SisGen e assinar o Termo de Compromisso (TC) com a União, representada neste ato pelo Ministro de Estado e Meio Ambiente, ou a quem este delegar (BRASIL, 2015).

O TC disponível no sítio eletrônico do Ministério do Meio Ambiente (MMA) deverá ser preenchido pelo usuário ou seu representante legal e 
remetido à Secretaria de Biodiversidade do Ministério do Meio Ambiente (BRASIL, 2017b). Na hipótese da atividade de acesso ao patrimônio genético ter sido realizada unicamente para fins de pesquisa científica, o usuário estará dispensado da assinatura do $\mathrm{TC}$, bastando a formalização do cadastro no SisGen (BRASIL, 2015; 2016).

Para as atividades de acesso com a participação de pessoa física ou jurídica estrangeira, realizadas em plataforma continental, águas jurisdicionais brasileiras, zona econômica exclusiva e áreas indispensáveis à segurança nacional, aqui compreendidas as faixas de fronteira e as ilhas oceânicas, o usuário está obrigado a solicitar a autorização no SisGen. Contudo, se o acesso ao PATGEN teve início entre 30.06.2000 e 16.11.2015 e somente foi finalizado após 17.11.2015, esta atividade deverá ser adequada apenas pela realização do cadastro no SisGen, desde que a atividade tenha cumprido todos os requisitos da MP até 16.11.2015. Caso a atividade aqui descrita esteja em desacordo com a MP, a regra é adotar o procedimento de regularização acima descrito (BRASIL, 2015; 2016).

Os pedidos de autorização ou de regularização de acesso e remessa realizados na vigência da MP devem ser reformulados junto ao SisGen no prazo de 1 ano, a contar de 6 de novembro de 2017 (BRASIL, 2015). Eventual pedido de depósito de patente efetuado até 16.11.2015, baseado em atividades realizadas durante a vigência da MP e em desacordo com esta, deverá ser regularizado junto ao Instituto Nacional de Propriedade Intelectual, por meio da apresentação de comprovante de cadastro ou de autorização, obtidos através do procedimento de regularização aqui descrito (BRASIL, 2015; 2016).

\subsection{Acesso ao conhecimento tradicional associado}

Outro conceito importante é aquele referente ao acesso ao conhecimento tradicional associado. $\mathrm{O}$ artigo $7^{\circ}, \mathrm{V}$ da $\mathrm{MP}$ define acesso ao conhecimento tradicional associado como:

\footnotetext{
“obtenção de informação sobre conhecimento ou prática individual ou coletiva, associada ao patrimônio genético, de comunidade indígena ou de comunidade local, para fins de pesquisa científica, desenvolvimento tecnológico ou bioprospecção, visando à sua aplicação industrial ou de outra natureza” (BRASIL, 2001).
}

A expressão "comunidade indígena" sempre foi considerada de 
fácil compreensão. No entanto, não existe uma conceituação precisa sobre "comunidades locais". Diversos autores consideram-nas como comunidades que mantêm uma estreita relação com a natureza e são dependentes dos recursos naturais locais para sua subsistência e para manutenção de seu modo de vida (DIEGUES, 1993; MORTUREUX, 2000; SANTILLI, 2002). Desta maneira, a caracterização de uma comunidade local não estaria em sua localização geográfica, uma vez que esta poderia ser encontrada inclusive em meios urbanos, mas sim na forma de vida e na simbiose com o meio ambiente, onde ocorrem vínculos sociais, econômicos, culturais, espirituais e outros (MOREIRA, 2007).

$\mathrm{O}$ artigo $7^{\circ}$, inciso III da MP, conceitua comunidade local como:

\begin{abstract}
"grupo humano, incluindo remanescentes de comunidades de quilombos, distinto por suas condições culturais, que se organiza, tradicionalmente, por gerações sucessivas e costumes próprios, e que conserva suas instituições sociais e econômicas" (BRASIL, 2001).
\end{abstract}

A definição trazida pela MP, aparentemente, excluía da proteção os agricultores tradicionais e as comunidades ribeirinhas (GODINHO e MACHADO, 2011).

Importante destacar que o Decreto $n^{0}$ 6.040/2007, que instituiu a Política Nacional de Desenvolvimento SustentáveldosPovoseComunidades Tradicionais, e no inciso I do artigo $3^{\circ}$ conceituou comunidade tradicional, aqui equiparada à comunidade local, como: "[...] grupos culturalmente diferenciados e que se reconhecem como tais, que possuem formas próprias de organização social, que ocupam e usam territórios e recursos naturais como condição para sua reprodução cultural, social, religiosa, ancestral e econômica, utilizando conhecimentos, inovações e práticas gerados e transmitidos pela tradição" (BRASIL, 2007a).

Com base no conceito trazido pelo Decreto de 2007 (BRASIL, 2007a), pode-se considerar incluídos no rol de comunidades locais, quando preenchidas as premissas contidas na MP, os quilombolas, extrativistas, ribeirinhos, pescadores artesanais, quebradeiras-de-coco-babaçu, seringueiros, pantaneiros, geraizeiros, vazanteiros, comunidades de fundo de pasto, faxinalenses e caiçaras (VASCONCELOS, 2012).

Como regra geral, os pequenos produtores e os assentados não estariam enquadrados dentro do conceito de comunidade local para fins da proteção outorgada pela MP, em razão da ausência dos requisitos de 
condições culturais distintas, organização tradicional repassada por gerações sucessivas e costumes próprios (VASCONCELOS, 2012).

Destaca-se, para efeitos de ajuste das atividades, que o conhecimento tradicional a ser considerado é aquele que proporcionou ou facilitou o acesso a material genético ou a confecção de seus produtos (LAVRATTI, 2007). Como exemplos de acesso ao conhecimento tradicional associado podem-se citar os conhecimentos sobre as propriedades farmacêuticas, alimentícias e agrícolas de espécies da flora e fauna, as técnicas de manejo, dentre outros (DERANI, 2012; SANTILLI, 2005).

Diante da imprecisão conceitual da MP, a análise do enquadramento de uma comunidade no conceito de comunidade local deverá ser realizada de forma minuciosa, a fim de não se excluir uma determinada população do âmbito de proteção da MP, já que não existe um rol taxativo que define quais comunidades eram consideradas locais ou tradicionais.

Realizada a definição do perfil das comunidades protegidas pela MP, resta saber quais ações eram consideradas acesso ao conhecimento tradicional associado.

Considerando-se a delimitação trazida pela MP e, fazendo uso do conceito abstrato imbuído na palavra "acesso", pode-se concluir que a obtenção da informação não necessitaria ser extraída diretamente de uma determinada comunidade. A informação também poderia ser retirada de um artigo de jornal ou outras fontes, desde que capaz de facilitar ou possibilitar o acesso ao material genético. Como exemplo, pode-se citar um artigo de jornal que relata a vida de uma determinada comunidade indígena, do estado de Roraima, e insere em seu texto que as sementes de um fruto são utilizadas há séculos pela comunidade como método contraceptivo. De posse desta informação, um laboratório coleta uma amostra da semente, isola e identifica a molécula detentora do princípio ativodesta amostra, elabora e patenteia medicamento anticoncepcional (BOFF, 2015).

Neste exemplo percebe-se que o laboratório acessou o conhecimento tradicional da comunidade indígena do estado de Roraima, o qual proporcionou um atalho de muitos anos e de alto custo em pesquisa para o desenvolvimento do medicamento e, portanto, deveria ter seguido os procedimentos previstos na MP, inclusive quanto à repartição dos benefícios resultantes da exploração econômica do produto.

Porém, a regularização da atividade não está restrita ao laboratório que se utilizou do conhecimento publicado, mas também incide sobre o autor da publicação a respeito da comunidade indígena. Conforme a norma 
de transição inserida no inciso IV do artigo 38 da Lei $n^{0}$ 13.123/2015, estaria obrigado a regularizar-se aquele que divulgou, transmitiu ou retransmitiu informações que integram ou constituem conhecimento tradicional associado (BRASIL, 2015).

\subsubsection{Procedimento de ajuste}

A forma de ajuste da atividade de acesso ao conhecimento tradicional associado é similar àquela já descrita no tópico 3.1.2, tanto na adequação, como na regularização e na reformulação.

Algumas diferenças, porém, merecem destaque. Para fins de ajuste da atividade, seguindo o exemplo acima, tanto o laboratório quanto o autor do artigo deveriam assinar um Termo de Compromisso (TC) com a União, em que estariam previstos, a depender do caso, o cadastro, a autorização de acesso ou de remessa, a notificação do produto acabado e a previsão de repartição de benefícios, conforme disposto nos artigos $38, \S 1^{\circ}$ e 39 da Lei $n^{\mathrm{o}}$ 13.123/2015 (BRASIL, 2015).

Entretanto, se o autor da publicação sobre a comunidade indígena elaborou o artigo única e exclusivamente para fins de pesquisa científica, será necessário apenas realizar o cadastro no SisGen, dispensando-se assinatura de TC (BRASIL, 2015).

\subsection{O acesso e exploração econômica de produto ou processo oriundo do} acesso ao PG ou CTA

O MLB enumerou as hipóteses em que a exploração econômica de itens oriundos da biota nacional deve ser reformulada, regularizada ou adequada. Em regra, a exploração econômica se concretiza com a emissão da nota fiscal pela comercialização de determinado item (BRASIL, 2016). Ao emitir a nota fiscal, nasce a obrigação de repartir os benefícios auferidos pela venda dos itens provenientes do patrimônio genético nacional. Em termos legais, a hipótese de incidência é a exploração econômica; o fato gerador é a emissão da nota fiscal (NF), e a consequência jurídica é a obrigação de repartir os benefícios.

Para o ajuste da atividade de exploração econômica, o primeiro ponto a se considerar é a data em que ocorreu o fato gerador: se foi na vigência da MP ou do MLB. Essa distinção é de extrema relevância, pois há distinção entre as atividades que eram consideradas como hipótese de 
incidência para a MP e para o MLB (FIGURA 2).

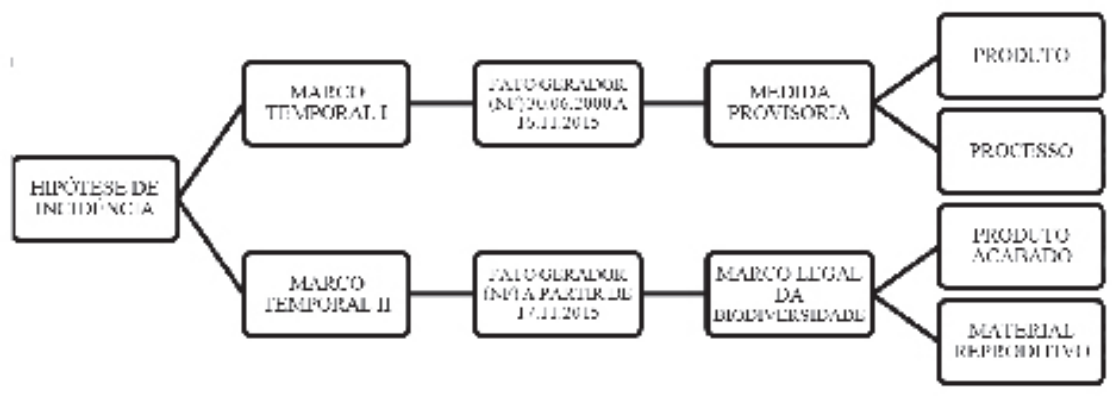

Figura 3. Descrição esquemática das hipóteses de exploração econômica nos dois marcos temporais.

Na figura 3, o marco temporal I compreende os fatos geradores ocorridos no período de vigência da MP (entre 30.06.2000 e 16.11.2015). Neste período, as hipóteses de incidência eram a exploração econômica de produto ou processo proveniente do patrimônio genético ou do conhecimento tradicional associado (BRASIL, 2001).

A MP no 2.186/2000 não delimitou o conceito de produto e de processo, restringindo-se a proteger, de forma ampla, a exploração econômica de produto e processo desenvolvido a partir do acesso de componentes do patrimônio genético e do conhecimento tradicional nacionais (BRASIL, 2001).

Por outro lado, o Marco temporal II compreende os fatos geradores ocorridos na vigência do MLB (após 17.11.2015), apenas para as atividades de exploração econômica de produto acabado ou de material reprodutivo (BRASIL, 2015).

Para fins de ajuste de atividades, somente será relevante neste momento o estudo do Marco Temporal I.

Observando-se os Marcos Temporais pode-se perceber que não há conflito entre a aplicação do MLB e a MP. Com base nos princípios da segurança jurídica e da não retroatividade da lei, as ações finalizadas na vigência de uma determinada norma devem ser por ela regidas, não se permitido que norma posterior altere definições e procedimentos para atos jurídicos considerados perfeitos, i.é, finalizados (MEIRELLES, 2016).

Assim, o ato jurídico da exploração econômica na MP é considerado perfeito, ou seja, finalizado, quando o usuário, aqui compreendido o 
explorador econômico, emite a Nota Fiscal pela comercialização do produto e possui Contrato de Utilização de Patrimônio Genético e de Repartição de Benefícios (CURB) registrado e anuído pelo CGEN (BRASIL, 2001). Para esta situação, nenhuma lei posterior pode determinar qualquer alteração (MEIRELLES, 2016). Por outro lado, ações pendentes de finalização neste período serão regidas pelas disposições transitórias do MLB.

Nota-se que o alcance da norma posterior ao fato pendente não é ilimitado, uma vez que não se pode alterar a parte consumada da ação. Uma lei nova poderia alterar as consequências de um fato pendente, mas não poderia alterar o fato em si (LEVADA, 2009).

Especificamente no Marco Temporal I desdobram-se quatro cenários (FIGURA 4):

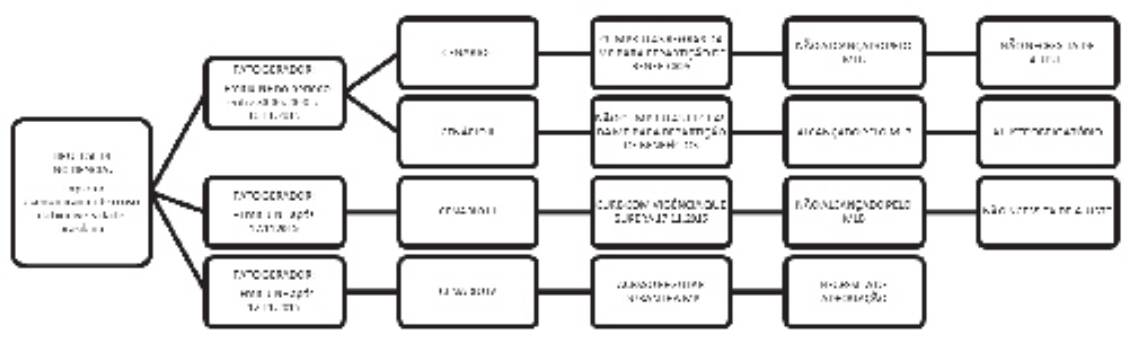

Figura 4. Descrição esquemática das hipóteses de incidência quando houver exploração econômica da biodiversidade

Conforme sintetizado na figura 4, no primeiro cenário os fatos são considerados perfeitos, pois foram finalizados de acordo e na vigência da MP. Por outro lado, no segundo cenário os fatos são considerados pendentes, pois foram realizados na vigência da $\mathrm{MP}$, mas em desacordo com a norma e, portanto, devem-se realizar ajuntes conforme a MLB.

O terceiro cenário compreende as situações em que o CURB possua validade superior à data de 17.11.2015, ou seja, a vigência da MP. Nesta situação, o decreto $\mathrm{n}^{\circ} 8.772 / 2016$ prevê, no parágrafo $2^{\circ}$ do artigo 103, que este contrato permanecerá válido pelo prazo nele previsto (BRASIL, 2016). Desta forma, toda a comercialização de produto ou processo compreendido nas hipóteses de incidência descritas no contrato e, enquanto este estiver válido, não sofrerá a incidência do MLB. No entanto, 
finalizado o prazo de validade do contrato, a continuidade da atividade de exploração econômica nele previsto deverá seguir as regras do MLB, tanto em relação ao procedimento de cadastro da atividade quanto em relação à partilha dos benefícios.

Por fim, o quarto cenário compreende as situações em que a atividade se iniciou regularmente durante a vigência da MP e perdurou após a sua revogação; por exemplo, quando o acesso ao PG ou CTA realizado regularmente durante a vigência da MP foi a base para o desenvolvimento de produto ou material reprodutivo após sua revogação. Neste cenário, há a necessidade não só de notificação do produto acabado ou do material reprodutivo, nos termos do MLB, bem como da repartição de benefícios. Neste último caso, o fato gerador (emissão da NF) ocorreu na vigência do MLB e, desta forma, deverá seguir os procedimentos estabelecidos no MLB para os casos de exploração econômica (BRASIL, 2016).

\subsubsection{Procedimento de ajuste}

A exploração econômica de produto ou processo descritos nos cenários II e IV deverão ser regularizados por meio da assinatura do Termo de Compromisso, a ser anuído pelo usuário e encaminhado à Secretaria de Biodiversidade do Ministério do Meio Ambiente (BRASIL, 2016; BRASIL, 2017b).

\subsection{Remessa ao exterior de amostra do $P G$}

Ao tratar sobre a remessa para o exterior de amostra do patrimônio genético, o capítulo das disposições transitórias do MLB determinou como fato gerador da obrigação a remessa irregular ocorrida entre $30.06 .2000 \mathrm{e}$ 17.11.2015 (i.é., aquela ocorrida durante a vigência da MP).

A Orientação Técnica ${ }^{\circ}$ 01/03 emitida pelo CGEN define remessa como sendo o envio propriamente dito ou o transporte de amostra de componente do patrimônio genético, permanente ou temporário, com o objetivo de constituir acesso para pesquisa científica, desenvolvimento tecnológico ou bioprospecção, com ou sem a transferência da responsabilidade pela amostra da instituição remetente para a instituição destinatária (BRASIL, 2003).

A nova definição apresentada pelo MLB para a atividade de remessa é mais restrita, apenas considerando remessa para fins legais 
quando a responsabilidade pela amostra for transferida para a instituição destinatária localizada no exterior. Pelas regras de hermenêutica jurídica, norma posterior não pode ampliar o conceito trazido para um fato gerador já ocorrido; porém, pode restringir o conceito (GAGLIANO e STOLZE, 2012). Desta forma, a remessa abrangida pelas disposições transitórias é aquela em que há a transferência de responsabilidade para a instituição destinatária localizada no exterior.

A transferência de amostra para prestação de serviço no exterior, com a finalidade de realização de pesquisa ou de desenvolvimento tecnológico, sem a transferência da responsabilidade para pessoa física ou jurídica estrangeira, está configurada no MLB como atividade de envio, a qual não necessita de ajuste.

\subsubsection{Procedimento de ajuste}

O usuário, como descrito nas disposições transitórias do MLB, deve assinar o Termo de Compromisso, nos moldes da Portaria $n^{\circ}$ 350/2017 expedida pelo MMA e cadastrar a atividade de remessa no SisGen, informando o uso pretendido (BRASIL, 2017b).

A remessa realizada por pessoa jurídica nacional com a participação de pessoa física ou jurídica estrangeira, realizada na plataforma continental, águas jurisdicionais brasileiras, zona econômica exclusiva e áreas indispensáveis à segurança nacional (compreendendo as faixas de fronteira e as ilhas oceânicas), necessita de autorização a ser formulada no SisGen (BRASIL, 2015; 2016).

2.5 Divulgação, transmissão ou retransmissão de dados ou informações que integram ou constituem CTA

Um dos pontos mais delicados das disposições transitórias inseridas no MLB refere-se à dificuldade que o usuário tem de se identificar com a ação. Isso porque, quando se fala em patrimônio genético, em regra, o tema é associado às áreas de ciências biológicas e agrárias, afastando por completo a relação do tema com outras áreas, tais como as ciências humanas e sociais aplicadas. Porém, quando a MP e as disposições transitórias do MLB tratam sobre a divulgação, transmissão e retransmissão do conhecimento tradicional associado ao patrimônio genético, o alcance da norma se amplia, podendo atingir todas as áreas do conhecimento. 
Retomando o exemplo da comunidade indígena de Roraima, tratado no tópico 3.2, o conhecimento tradicional associado foi acessado, divulgado e, posteriormente, utilizado. Suponha-se que a divulgação tenha ocorrido na apresentação do resultado de um estudo sobre o comportamento daquela comunidade indígena, onde a menção ao uso da semente foi realizada sem qualquer pretensão, apenas como um relato sobre as peculiaridades daquela comunidade. Neste caso, o pesquisador que divulgou o estudo deve realizar o ajuste de sua atividade.

\subsubsection{Procedimento de ajuste}

$\mathrm{Na}$ hipótese de divulgação, transmissão ou retransmissão de informações que constituem um CTA ao patrimônio genético, a única forma de ajuste é a regularização, ou seja, quando essa atividade foi realizada entre 30.06.2000 e 16.11.2015, em desacordo com as regras da MP.

A regularização, como dito anteriormente, deve ser realizada mediante cadastro no SisGen e assinatura de Termo de Compromisso. No entanto, quando a atividade for desenvolvida unicamente para fins de pesquisa científica, o usuário estará dispensado da assinatura do TC, bastando para a regularização a realização no cadastro no SisGen.

\subsection{Pedidos de autorização e regularização que estavam em tramitação na entrada em vigor do MLB}

O MLB é claro quanto às situações em que o usuário havia solicitado, durante a vigência da MP, a autorização para realização de suas atividades de acesso e remessa do PG e do CTA ou a regularização das atividades já desenvolvidas, porém, ainda aguardava a finalização dos trâmites quando o MLB entrou em vigor. Para esses casos, o artigo 35 da Lei $\mathrm{n}^{\circ} 13.123$ determina que o usuário deverá reformular os pedidos junto ao SisGen, dentro do prazo de 1 ano, a contar da data de disponibilização do sistema (BRASIL, 2015).

\section{CONCLUSÃO}

O presente artigo descreveu as atividades a serem ajustadas e os procedimentos para o cumprimento das normas transitórias do MLB. Embora aparentemente simples, os conceitos e delimitações das atividades 
e procedimentos descritos no MLB apresentam diversos detalhes que conduzem a diferentes formas de reformulação, adequação e regularização. A não observância de tais especificidades pode levar o usuário a equívocos, uma vez que as ações a serem ajustadas segundo a nova legislação devem se limitar às definições a elas relacionadas na época da vigência da MP. Assim, compreendendo-se e identificando-se as atividades abrangidas pelo MLB e seus marcos temporais descritos neste artigo, permite-se que o usuário da biodiversidade vislumbre, entre suas atividades já realizadas, quais deverão ser ajustadas e quais não estão abrangidas pelas normas de transição.

\section{REFERÊNCIAS}

AZEVEDO, C. M. A. A. Regulamentação do acesso aos recursos genéticos e aos conhecimentos tradicionais associados no Brasil. Biota Neotropica, v.5, n.1, 2005.

BENSUSAN, N. Breve histórico da regulamentação do acesso aos recursos genéticos no Brasil. In: LIMA, A.; BENSUSAN, N. (Orgs.) Quem cala consente? Subsídios para proteção aos conhecimentos tradicionais. São Paulo: Instituto Socioambiental, 2003. p. 9-16.

BOFF, S. O. Acesso aos conhecimentos tradicionais: repartição de benefícios pelo 'novo'marco regulatório. Revista Direito Ambiental e sociedade, Caxias do Sul, v. 5, n. 2, p. 110-127, 2015.

BRASIL. Decreto Lei n ${ }^{\circ} 4.657$, de 4 de setembro de 1942. Lei de Introdução às normas do Direito Brasileiro. Diário Oficial [da] República Federativa do Brasil, Poder Executivo, Brasília, DF, 09 set. 1942. Disponível em: $<$ http://www.planalto.gov.br/ccivil_03/decreto-lei/Del4657.htm> Acesso em 10 mai. 2017.

- Presidência da República. Constituição da República Federativa do Brasil: promulgada em 5 de outubro de 1988. Diário Oficial [da] República Federativa do Brasil, Poder Executivo, Brasília, DF, 05 out. 1988. Disponível em: <http://www.planalto.gov.br/ccivil_03/constituicao/ constituicao.htm> Acesso em 12 set. 2017.

. Lei $\mathrm{n}^{\mathrm{o}} 8.617$, de 04 de janeiro de 1993. Dispõe sobre o mar territorial, a zona contígua, a zona econômica exclusiva e a plataforma continental 
brasileiros, e dá outras providências. Diário Oficial [da] República Federativa do Brasil, Poder Executivo, Brasília, DF, 05 jan. 1993. Disponível em: <http://www.planalto.gov.br/ccivil_03/leis/L8617.htm> Acesso em 12 jun. 2017.

. Decreto Legislativo $n^{\circ} 02$ de 03 de fevereiro de 1994. Aprova o texto da Convenção sobre Diversidade Biológica, assinado durante a Conferência das Nações Unidas sobre Meio Ambiente e Desenvolvimento, realizada na Cidade do Rio de Janeiro, no período de 5 a 14 de junho de 1992. Diário Oficial [da] República Federativa do Brasil, Poder Executivo, Brasília, DF, 04 fev 1994. Disponível em: < http://www2.camara.leg. br/legin/fed/decleg/1994/decretolegislativo-2-3-fevereiro-1994-358280publicacaooriginal-1-pl.html>. Acesso em 20 jul. 2017.

. Decreto Legislativo $\mathrm{n}^{\circ} 2.519$ de 16 de março de 1998. Promulga a Convenção sobre Diversidade Biológica, assinada no Rio de Janeiro, em 05 de junho de 1992. Diário Oficial [da] República Federativa do Brasil, Poder Executivo, Brasília, DF, 17 mar. 1998. Disponível em: $<$ http://www. planalto.gov.br/ccivil_03/decreto/d2519.htm>. Acessado em 20 ago. 2017.

. Medida Provisória 2.186-16, de 23 de agosto de 2001. Regulamenta o inciso II do $\S 1^{\circ}$ e o $\S 4^{\circ}$ do art. 225 da Constituição, os arts. $1^{\circ}, 8^{\circ}$, alínea "j", 10, alínea "c", 15 e 16, itens 3 e 4 da Convenção sobre Diversidade Biológica, dispõe sobre o acesso ao patrimônio genético, a proteção e o acesso ao conhecimento tradicional associado, a repartição de benefícios e o acesso à tecnologia e transferência de tecnologia para sua conservação e utilização, e dá outras providências. Diário Oficial [da] República Federativa do Brasil, Poder Executivo, Brasília, DF, 24 ago 2001. Disponível em: <http://www.planalto.gov.br/ccivil_03/mpv/218616.htm>. Acesso em 20 jul. 2017.

- Ministério do Meio Ambiente. Conselho de Gestão do Patrimônio Genético. Orientação Técnica ${ }^{\circ} 01$, de 24 de setembro de 2003. Esclarece os conceitos de acesso e de remessa de amostras de componentes do patrimônio genético. Diário Oficial [da] República Federativa do Brasil, Poder Executivo, Brasília, DF, 24 out. 2004a. Disponível em: < http:// www.mma.gov.br/estruturas/sbf_dpg/_arquivos/ot1.pdf $>$ Acesso em 17 ago. 2017. 
. Ministério do Meio Ambiente. Conselho de Gestão do Patrimônio Genético. Orientação Técnica n ${ }^{\circ} 03$, de 30 de outubro de 2003. Estabelece o conceito de subamostra. Diário Oficial [da] República Federativa do Brasil, Poder Executivo, Brasília, DF, 15 jan. 2004b. Disponível em: < http://www.mma.gov.br/estruturas/sbf_dpg/_arquivos/ot2.pdf $>$ Acesso em 17 ago. 2017.

. Ministério do Meio Ambiente. Conselho de Gestão do Patrimônio Genético. Resolução ${ }^{\circ} 21$, de 31 de agosto de 2006. As seguintes pesquisas e atividades científicas não se enquadram sob o conceito de acesso ao patrimônio genético para as finalidades da Medida Provisória no 2.18616, de 23 de agosto de 2001. Diário Oficial da União, Brasília, DF, 12 set. 2006. Seção 1, p. 118.

. Decreto Lei $n^{\circ}$ 6.040, de 7 de fevereiro de 2007. Institui a Política Nacional de Desenvolvimento Sustentável dos Povos e Comunidades Tradicionais. Diário Oficial [da] República Federativa do Brasil, Poder Executivo, Brasília, DF, 08 fev. 2007a. Disponível em: < http://www. planalto.gov.br/ccivil_03/_ato2007-2010/2007/decreto/d6040.htm> Acesso em 10 mai. 2017.

. Ministério do Meio Ambiente. Conselho de Gestão do Patrimônio Genético. Resolução $\mathrm{n}^{\mathrm{o}}$ 26, de 30 de agosto de 2007. As variedades cultivadas comerciais de cana-de-açúcar, Saccharum spp., inscritas no Registro Nacional de Cultivares - RNC, do Ministério da Agricultura, Pecuária e Abastecimento, não se caracterizam como patrimônio genético do País para as finalidades da Medida Provisória n ${ }^{\circ}$ 2.186-16, de 23 de agosto de 2001. Diário Oficial da União, Brasília, DF, 24 dez. $2007 \mathrm{~b}$. Seção 1, p. 102.

. Ministério do Meio Ambiente. Conselho de Gestão do Patrimônio Genético. Resolução $n^{\circ} 28$, de 06 de novembro de 2007. Altera o art. $1^{\circ}$ da Resolução $\mathrm{n}^{\circ}$ 21, de 31 de agosto de 2006. Diário Oficial da União, Brasília, DF, 10 dez. 2007c. Seção 1, p. 77.

- Ministério do Meio Ambiente. Conselho de Gestão do Patrimônio Genético. Resolução $n^{\circ}$ 29, de 06 de dezembro de 2007. Dispõe sobre o enquadramento de óleos fixos, óleos essenciais e extratos, no âmbito da Medida Provisória n ${ }^{\circ}$.186-16, de 23 de agosto de 2001. Diário Oficial da União, Brasília, DF, 27 dez. 2007d. Seção 1, p. 167. 
. Decreto $\mathrm{n}^{\mathrm{o}}$ 6.476, de 5 de junho de 2008. Promulga o Tratado Internacional sobre Recursos Fitogenéticos para a Alimentação e a Agricultura, aprovado em Roma, em 3 de novembro de 2001, e assinado pelo Brasil em 10 de junho de 2002. Diário Oficial [da] República Federativa do Brasil, Poder Executivo, Brasília, DF, 06 jun. 2008. Disponível em: $<$ http://www.planalto.gov.br/ccivil_03/_ato2007-2010/2008/decreto/ d6476.htm> Acesso em 17 ago. 2017.

Ministério do Meio Ambiente. Conselho de Gestão do Patrimônio Genético. Orientação Técnica $n^{\circ} 08$, de 11 de dezembro de 2012. Esclarece sobre a aplicabilidade do Tratado Internacional sobre Recursos Fitogenéticos para a Alimentação e a Agricultura sobre as espécies listadas em seu Anexo I. Diário Oficial da União, Brasília, DF, 14 jun. 2013. Seção 1, p. 67.

. Ministério do Meio Ambiente. Conselho de Gestão do Patrimônio Genético. Orientação Técnica n ${ }^{\circ}$ 09, de 17 de setembro de 2013. Esclarece que o uso de parasitas, pragas e vetores de doenças para as atividades descritas não configura acesso ao patrimônio genético no âmbito da MP $n^{\circ}$ 2.186- 16/2001. Diário Oficial da União, Brasília, DF, 26 mar. 2014a. Seção 1, p. 94.

. Ministério do Meio Ambiente. Conselho de Gestão do Patrimônio Genético. Orientação Técnica ${ }^{\circ} 10$, de 22 de maio de 2014. Esclarece as atividades realizadas em bancos de dados nacionais e internacionais de domínio público. Diário Oficial da União, Brasília, DF, 31 out. 2014b. Seção 1, p. 86.

. Lei $\mathrm{n}^{\circ} 13.123$, de 20 de maio de 2015. Regulamenta o inciso II do $\S 1$ o e o $\S 40$ do art. 225 da Constituição Federal, o Artigo 1, a alínea j do Artigo 8, a alínea c do Artigo 10, o Artigo 15 e os $\S \S 3 o$ e 4o do Artigo 16 da Convenção sobre Diversidade Biológica, promulgada pelo Decreto no 2.519 , de 16 de março de 1998; dispõe sobre o acesso ao patrimônio genético, sobre a proteção e o acesso ao conhecimento tradicional associado e sobre a repartição de benefícios para conservação e uso sustentável da biodiversidade; revoga a Medida Provisória n ${ }^{\circ}$ 2.186-16, de 23 de agosto de 2001; e dá outras providências. Diário Oficial [da] República Federativa do Brasil, Poder Executivo, Brasília, DF, 14 mai. 2015. Disponível em: $<$ http://www.planalto.gov.br/ccivil_03/_Ato2015-2018/2015/Lei/L13123. htm>. Acesso em 02 jun. 2017. 
. Decreto Lei $\mathrm{n}^{\circ} 8772$, de 11 de maio de 2016. Regulamenta a Lei $\mathrm{n}^{\circ}$ 13.123 , de 20 de maio de 2015, que dispõe sobre o acesso ao patrimônio genético, sobre a proteção e o acesso ao conhecimento tradicional associado e sobre a repartição de benefícios para conservação e uso sustentável da biodiversidade. Diário Oficial [da] República Federativa do Brasil, Poder Executivo, Brasília, DF, 12 mai. 2016. Disponível em: < http://www. planalto.gov.br/ccivil_03/_Ato2015-2018/2016/Decreto/D8772.htm>. Acesso em 12 jun. 2017.

- Ministério da Agricultura, Pecuária e Abastecimento. Gabinete do Ministro. Instrução Normativa n ${ }^{\circ} 23$, de 14 de junho de 2017. Torna pública a lista de referência de espécies vegetais domesticadas ou cultivadas que foram introduzidas no território nacional. Diário Oficial da União, Brasília, DF, 16 jun. 2017a. Seção 1, p. 5.

. Ministério do Meio Ambiente. Conselho de Gestão do Patrimônio Genético. Portaria $\mathrm{n}^{\mathrm{o}} 350$, de 08 de setembro de 2017. Aprova os instrumentos de Termos de Compromisso a serem firmados entre o usuário e a União, para fins de regularização do acesso ao patrimônio genético e ao conhecimento tradicional associado, nos termos da Lei $\mathrm{n}^{\circ} 13.123$, de 20 de maio de 2015. Diário Oficial da União, Brasília, DF, 11 set. 2017b. Seção 1, p. 39.

. Ministério do Meio Ambiente. Conselho de Gestão do Patrimônio Genético. Orientação Técnica n ${ }^{\circ}$ 02, de 28 de junho de 2017. Diário Oficial da União, Brasília, DF, 25 set. 2017c. Seção 1, p. 99.

. Ministério do Meio Ambiente. Conselho de Gestão do Patrimônio Genético. Secretaria Executiva. Implementa e disponibiliza o Sistema Nacional de Gestão do Patrimônio Genético e do Conhecimento Tradicional Associado - SisGen a partir de 6 de novembro de 2017d. Diário Oficial da União, Brasília, DF, 13 out. 2017c. Seção 1, p. 78.

DERANI, C.Estudos sobre acesso aos recursos genéticos da biodiversidade, conhecimentos tradicionais associados e repartição de beneficios - interpretação da Medida Provisória 2.186-16/2001. Florianópolis: Fundação Boiteux, 2012.

DIEGUES, A. C. S. Populações tradicionais em unidades de conservação: o mito moderno da natureza intocada. In: Populações tradicionais em 
unidades de conservação: o mito moderno da natureza intocada. São Paulo: CEMAR/USP/NUPAUB, 1993.

FERREIRA, S. N.; CLEMENTINO, A. N. R. Legislação de acesso a recursos genéticos e conhecimentos tradicionais associados e repartição de benefícios. Brasília: EMBRAPA, 2010.

FERREIRA, S. N.; SAMPAIO, M. J. A. M. Biodiversidade e conhecimentos tradicionais associados: implementação da legislação de acesso e repartição de benefícios no Brasil. Brasília: SBPC, v. 356, 2013.

FERRO, A. F. P., BONACELLI, M. B. M.; ASSAD, A. L. D. Oportunidades tecnológicas e estratégias concorrenciais de gestão ambiental: o uso sustentável da biodiversidade brasileira. Gestão \& Produção, v. 13, n. 3, p. 489-501, set./dez. 2006.

GAGLIANO, P. S.; PAMPLONA FILHO, R. Novo curso de direito civil, São Paulo: Saraiva, v. 1, 2012.

GUERRA, M. P.; ROCHA, F. S.; NODARI, R. O. Biodiversidade, recursos genéticos vegetais e segurança alimentar em cenário de ameaças e mudanças. In: VEIGA, R. F. A.; QUEIRÓZ, M. A. (Orgs.). Recursos fitogenéticos: a base da agricultura sustentável no Brasil. Viçosa: UFV, 2015. p. 39-52.

GODINHO, R. S.; MACHADO, C. J. S. Avanços e percalços na elaboração da legislação nacional sobre acesso a recursos genéticos e aos conhecimentos tradicionais associados. Desenvolvimento e Meio Ambiente, n. 24, p. 8399, 2011.

JUSTEM FILHO, M. Curso de Direito Administrativo. São Paulo: Saraiva, 2010 .

LAVRATTI, P. C. Acesso ao patrimônio genético e aos conhecimentos tradicionais associados.http://igeologico.sp.gov.br/wp-content/uploads/ cea/Texto Paula.pdf (acessado em 20/05/2017).

LENZA, P. Direito Constitucional Esquematizado. 19a ed. São Paulo: Saraiva, 2015.

LEVADA, F. A. M. O direito intertemporal e os limites da proteção do direito adquirido. São Paulo, 2009. Tese (Doutorado em Direito) - 
Faculdade de Direito, Universidade de São Paulo.

LEWINSOHN, T. M.; PRADO, P. I. Síntese do conhecimento atual da biodiversidade brasileira. In: LEWINSOHN, T. M. (Org.). Avaliação do Estado do Conhecimento da Biodiversidade Brasileira, Biodiversidade. v. 1, p.21-109. Ministério do Meio Ambiente, 2006.

MEIRELLES, H. L. Direito Administrativo Brasileiro. 42 ${ }^{\text {a }}$ Ed. São Paulo: Malheiros, 2016.

MENUCHI, L. N. S.; AMARANTE SEGUNDO, G. S.; DE ARAUJO, J. C. O novo marco legal para acesso ao patrimônio genético e proteção e acesso ao conhecimento tradicional associado. GEINTEC-Gestão, Inovação e Tecnologias, v. 6, n. 1, p. 2954-2965, 2016.

MITTERMEIER,R.A.;GIL,P.R.; MITTERMEIER,C.G. Megadiversidad: los países biológicamente más ricos del mundo. $1^{\circ}$ ed. México: Cementos Mexicanos, 1997.

SACCARO JR, N. L. A regulamentação de acesso a recursos genéticos e repartição de benefícios: disputas dentro e fora do Brasil. Ambiente \& Sociedade, v. 14, n. 1, p. 229-244, 2011.

MOREIRA, E. Conhecimentos tradicionais e sua proteção. T\&CAmazônia, Manaus,ano V, n. 11, p. 33-41, 2007.

MOREIRA, E. C. P. As violações de direitos aportadas pela lei n. ${ }^{\circ}$ 13.123/2015 como ofensa ao princípio de vedação de retrocesso dos direitos humanos. In: MOREIRA, E. C. P.; PORRO, N. M.; SILVA, L. A L. da. (Orgs.) A "nova" lei $n .{ }^{\circ} 13.123 / 2015$ no velho marco legal da biodiversidade: entre retrocessos e violações de direitos socioambientais. São Paulo: Câmara Brasileira do Livro, 2017. p. 231 a 236.

MORTUREUX, V. Droits de propriété intellectuelle et connaissances, innovations et pratiques des communautés autochtones et locales. Paris: BRG, Bureau des ressources génétiques, 2000.

NADER, H. B.; OLIVEIRA, F. de; MOSSRI, B. B. A ciência e o poder legislativo: relatos e experiências. São Paulo: SBPC, 2017.

SANTILLI, J. Biodiversidade e conhecimentos tradicionais associados: novos avanços e impasses na criação de regimes legais de proteção. In: 
BENSUSAN, N.; LIMA, A. (Orgs.) Quem cala consente? Subsídios para a proteção aos conhecimentos tradicionais. São Paulo: Instituto Socioambiental, 2003, p. 53-74

SANTILLI, J. Mecanismos de proteção dos conhecimentos tradicionais e repartição de benefícios. In. BELAS, C. A.; MOREIRA, E.; BARROS, B. (Orgs.) Seminário Saber Local/Interesse Global: propriedade intelectual, biodiversidade e conhecimento tradicional na Amazônia, Anais..., Belém: CESUPA: MPEG, 2005.

VASCONCELOS, R. M. de. Marco regulatório sobre acesso à amostra de patrimônio genético nativo e acesso ao conhecimento tradicional associado. Brasília: Embrapa, 2012.

TÁVORA, F. L.; FRAXE NETO, H. J.; PÓVOA, L. M. C.; KASSMAYER, K.; SOUZA, L. B. G. D.; PINHEIRO, V. M.; BASILE, F.; CARVALHO, D. M. N.de. Comentários à Lei $n^{\circ} 13.123$, de 20 de maio de 2015: Novo Marco Regulatório do Uso da Biodiversidade. Brasília: Núcleo de Estudos e Pesquisas/CONLEG/Senado, outubro/2015 (Texto para Discussão $\mathrm{n}^{\mathrm{o}}$ 184). Disponível em: www.senado.leg.br/estudos. Acesso em 20 de outubro de 2015.

Artigo recebido em: 04/02/2018.

Artigo aceito em: 25/07/2018.

\section{Como citar este artigo (ABNT):}

SEGUNDO, G. S. A.; MENUCHI, L. N. S.; MENUCHI, M. R. T. P.; KANETO, C. M. O MARCO LEGAL DA BIODIVERSIDADE E SUA APLICAÇÃO NA REGULARIZAÇÃO DAS ATIVIDADES COM O USO DO PATRIMÔNIO GENÉTICO BRASILEIRO. Veredas do Direito, Belo Horizonte, v. 15, n. 32, p. 297-325, ma./ago. 2018. Disponível em: <http:// www.domhelder.edu.br/revista/index.php/veredas/article/view/1268>. Acesso em: dia mês. ano. 